\title{
Characterization of Lamprey Fibrinopeptides
}

\author{
By R. F. DOOLITTLE* \\ Coagulation Research Laboratory, Chemistry Department II, Karolinska Institutet, \\ Stockholm, Sweden
}

(Received 7 September 1964)

\begin{abstract}
1. Lamprey fibrinopeptide $B$ is a relatively large peptide made up of about 40 amino acid residues. The peptide is highly electronegative, containing a large number of aspartic acid residues and a tyrosine $O$-sulphate residue. 2. The amino acid sequence of the first 18 residues from the $N$-terminal end of fibrinopeptide $B$ has been established. The $C$-terminal ends with the sequence Val-Arg. Fibrinopeptide $B$ is released by both lamprey and bovine thrombins. 3. Lamprey fibrinopeptide $A$ is a short peptide containing only eight residues. The proposed amino acid sequence is :
\end{abstract}

Asp-Asp-Ser-Ile/Leu-Asp-Ser-Leu/Ile-Arg

This peptide is released by lamprey thrombin but not by bovine thrombin.

Evidence has been submitted showing that at least two fibrinopeptides are released from lamprey fibrinogen by lamprey thrombin (Doolittle, 1965). Only one of these is released by bovine thrombin during its transformation of the lamprey fibrinogen into fibrin. Characterization of these fibrinopeptides represents a first step in attempting to find out why and how the specificities of the two thrombins differ. In the present paper results are presented to show that both fibrinopeptides have arginine residues at the $C$-terminal end. Since only $N$-terminal glycine groups appear during the transformation of lamprey fibrinogen into fibrin, it is evident that only arginyl-glycine bonds are split during the release of both peptides. Fibrinopeptide $A$, which is not released by the bovine thrombin, has aspartic acid as its $N$-terminal residue. Fibrinopeptide $B$ has glutamic acid as its $N$-terminal residue and is split off by both thrombins. Fibrinopeptide $B$ is shown to be definitely homologous to mammalian fibrinopeptides $B$, since it contains the unusual amino acid derivative tyrosine $O$-sulphate, an amino acid found in a variety of mammalian fibrinopeptides $B$. Further, the amino acid sequence in the area of the sulphated tyrosine is identical with that found in mammalian fibrinopeptides $B$.

\section{MATERIALS AND METHODS}

Lamprey thrombin and fibrinogen. Full details on the purification of lamprey thrombin and fibrinogen, as well as

* Present address: Department of Biology, University of California, San Diego, Calif., U.S.A. for the clotting of the fibrinogen by lamprey or bovine thrombin, have been presented by Doolittle (1965).

Column chromatography. Dowex 50 (X2; 200-400 mesh) ion-exchange resin was pretreated according to the method of Hirs, Moore \& Stein (1956). Columns were equilibrated with 0.1 M-ammonium formate buffer, pH 3.0. Peptides were eluted by stepwise changes of buffers in the direction of

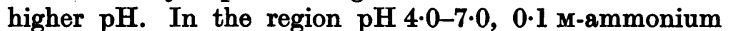
acetate buffers were used. Dowex 1 (X2) was converted first into the $\mathrm{OH}^{-}$form with $\mathrm{N}-\mathrm{NH}_{3}$ and then into the acetate form with acetic acid. It was finally equilibrated with $0 \cdot 1 \mathrm{M}$-ammonium acetate buffer, $\mathrm{pH} 5 \cdot 5$. Stepwise elution was accomplished by changes to appropriate volatile buffers at lower pH. Fractions were freeze-dried and samples examined for peptides in the paper-electrophoresis system. Sephadex G-25 (Pharmacia, Uppsala, Sweden) columns were poured after allowing the gel particles to swell in $1 \% \mathrm{NaCl}$ solution followed by extensive washing with distilled water. Fine particles were removed by decantation. The Sephadex columns were equilibrated and developed with 0.05 m-pyridine. Column development was monitored in all cases by subjecting samples from each fraction to alkaline hydrolysis followed by ninhydrin analysis according to the method of Moore \& Stein $(1954 a, b)$.

Amino acid determinations. Peptides were hydrolysed in twice-distilled $5 \cdot 7 \mathrm{~N}-\mathrm{HCl}$ at $110^{\circ}$ for $20 \mathrm{hr}$. Sample tubes were thoroughly flushed with nitrogen gas before sealing. The $\mathrm{HCl}$ was removed under reduced pressure in a desiccator containing $\mathrm{NaOH}$ pellets. If the samples were to be subjected to quantitative measurement by column chromatography, a volume of water equal to the original volume of the hydrolysis solution was added to the sample and the drying operation repeated three times. If the samples were to be subjected to qualitative analysis by combination paper electrophoresis-paper chromatography, the rinsing procedure was not necessary. Instead, the residues were dissolved in $25 \mu \mathrm{l}$. of water and applied to a spot in the centre of $4 \mathrm{~cm}$.-wide paper-electrophoresis strips (Schleicher 
and Schull no. 2043). Electrophoresis was conducted in $0 \cdot 1 \mathrm{~m}$-pyridine-acetic acid buffer, $\mathrm{pH} 4 \cdot 1$, at $300 \mathrm{v}$ for $4 \mathrm{hr}$. at room temperature. Papers were dried in an oven at $80^{\circ}$ and then stitched to Whatman 3MM paper for ascending chromatography in butan-1-ol-acetic acid-water $(4: 1: 5$, by vol.) for $17 \mathrm{hr}$. After being thoroughly dried, papers were stained with McMenamy's differential-colour ninhydrin reagent (McMenamy, Lund \& Oncley, 1957). Alkaline hydrolysis was conducted in $0.2 \mathrm{M}-\mathrm{Ba}(\mathrm{OH})_{2}$ at $115-120^{\circ}$ for $20 \mathrm{hr}$. The $\mathrm{Ba}(\mathrm{OH})_{2}$ solution was made up with hot water and filtered with a stemless funnel just before use. Tubes were sealed immediately. The hydrolysate (usually $50 \mu 1$.) was applied directly to the paperelectrophoresis strips for analysis by combination paper electrophoresis-paper chromatography. The applications were made to the dry papers, and the buffer was allowed to approach from each extremity. A smooth gel tends to form at the spot of application of the $\mathrm{Ba}(\mathrm{OH})_{2}$ solution, but this does not influence the subsequent migration of amino acids. In those experiments in which it was desirable to identify tyrosine $O$-sulphate, the $\mathrm{pH}$ was lowered to 3.9 to effect better separation of the tyrosine $O$-sulphate from aspartic acid. Reference tyrosine $O$-sulphate was a gift from Dr B. Blombäck. Quantitative analyses of acid hydrolysates of fibrinopeptides A and B were performed on a microchromatographic apparatus fashioned and operated by A. Baldesten. The single-column (Amberlite IR-120) development is based on the method of Spackman, Stein \& Moore (1958), but it is possible to measure amino acids with reasonable accuracy at the level of 0.02 $\mu$ mole. The column $(0.3 \mathrm{~cm} . \times 175 \mathrm{~cm}$; resin particle size, 20-30 $\mu$ ) was operationally similar to that described by Hamilton (1963). Samples for analysis were dissolved in a pH 2.2 buffer, and the initial elution was carried out at $\mathrm{pH} 3 \cdot 0$. The appearance of the glutamic acid peak on the recorder served as a signal to shift the elution over to a gradient system beginning at $\mathrm{pH} 3.46$ and increasing to pH 6.0. The author is indebted to A. Baldesten and N. R. Kale for designing the apparatus used.

Enzymic degradation of peptides. Twice-recrystallized trypsin and chymotrypsin were dissolved in $0.1 \mathrm{M}$ -

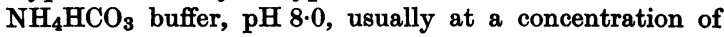
$0.1 \mathrm{mg}$. of enzyme/ml. of buffer. The enzyme:substrate ratio was about 1:50 on a weight basis. Incubations were carried out at $37^{\circ}$ for $5 \mathrm{hr}$. Samples, and the appropriate enzyme blanks and controls, were applied directly to $4 \mathrm{~cm}$.-wide paper-electrophoresis strips (dry loading), and subjected to electrophoresis in $0.1 \mathrm{~m}$-pyridine-acetic acid buffer, pH $4 \cdot 1$, at $300 \mathrm{v}$ for $4 \mathrm{hr}$. Guide strips about $2 \mathrm{~mm}$. wide were cut from each paper and stained with the McMenamy ninhydrin stain. Areas corresponding to the ninhydrin-positive bands were eluted with water, the material was freeze-dried and hydrolysed in acid, and the qualitative amino acid compositions were determined. Alternatively, in some experiments the digests were streaked on chromatography paper (Whatman no. 1) and subjected to descending chromatography in butan-1-ol-acetic acidwater (4:1:5, by vol.). Carboxypeptidase A (Sigma Chemical Co., St. Louis, Mo., U.S.A.) and carboxypeptidase B (Worthington Biochemical Corp., Freehold, N.J., U.S.A.) were also used in $0 \cdot 1 \mathrm{~m}-\mathrm{NH}_{4} \mathrm{HCO}_{3}$ buffer, $\mathrm{pH} 8.0$. Neither of the preparations was treated with di-isopropyl phosphorofluoridate, and the carboxypeptidase $B$ preparation was found to contain chymotryptic and carboxy-
peptidase-A activities. Incubations were carried out at room temperature, and samples were removed periodically and spotted or streaked directly on paper strips for analysis by combination paper electrophoresis-paper chromatography.

Subtilisin was a generous gift from $S$. Paleus. The enzyme was dissolved in $0.1 \mathrm{M}-\mathrm{NH}_{4} \mathrm{HCO}_{3}$ buffer, pH 8.0, at a concentration of $0.2 \mathrm{mg} . / \mathrm{ml}$. of buffer and the digestions were carried out for $18 \mathrm{hr}$. at room temperature. The entire incubation mixture was 'dry-loaded' on to paperelectrophoresis strips and electrophoresis conducted in

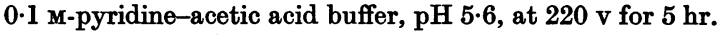
Guide strips were stained and the areas corresponding to the ninhydrin-positive bands eluted as described above.

Partial acid hydrolysis. The enzymic studies were supplemented by partial-hydrolysis studies with $1 \%$ acetic acid, $\mathrm{pH} 2 \cdot 8$, in sealed tubes at $110^{\circ}$ for $16 \mathrm{hr}$. Only aspartic acid links were appreciably split with this method (cf. Blackburn \& Lee, 1954). It was found convenient to 'dry-load' the partial hydrolysates directly on to electrophoresis papers. They were analysed for free amino acids and peptides in the combination system and also were run in the electrophoresis system alone for the elution of components.

Edman degradations. The Edman (1950) reaction was carried out in its three-cycle form (Edman, 1960) in an experimental manner designed by $\mathbf{P}$. Edman (unpublished modification). Samples for degradation ranging from 3 to $15 \mathrm{mg}$. were dissolved in $1.0 \mathrm{ml}$. of a $0.4 \mathrm{M}$-dimethylallylamine buffer, $\mathrm{pH} 9.6(15.0 \mathrm{ml}$. of pyridine, $10.0 \mathrm{ml}$. of water and $1.18 \mathrm{ml}$. of dimethylallylamine). Then $50 \mu \mathrm{l}$. of distilled phenyl isothiocyanate was added and the $\mathrm{pH}$ of the reaction mixture adjusted to 9.0 with dilute aqueous trifluoroacetic acid. The dipping electrode of the Radiometer pH-meter was rinsed with a few drops of dimethylallylamine buffer, $\mathrm{pH} \mathrm{9.0,} \mathrm{and} \mathrm{the} \mathrm{rinsings} \mathrm{were} \mathrm{added} \mathrm{to}$ the reaction mixture. The tubes were flushed for a few seconds with nitrogen, stoppered with glass and incubated at $40^{\circ}$ for $1 \mathrm{hr}$. The mixture was then washed thoroughly with 2-4 ml. of benzene five times, the organic phases being discarded. The last traces of benzene were removed with a stream of nitrogen. About $0.5 \mathrm{ml}$. of water was added to the aqueous phase and the system freeze-dried from a desiccator containing $\mathrm{NaOH}$ and $\mathrm{P}_{2} \mathrm{O}_{5}$ for at least $2 \mathrm{hr}$. The resulting residues were carefully washed three times with $0.5 \mathrm{ml}$. of ethyl acetate each time. Final traces of ethyl acetate were removed by gentle aspiration and then by placing the tubes in a desiccator under reduced pressure. The phenylthiocarbamoyl derivatives of the peptides were then dispersed in a minimal volume $(25-100 \mu 1$.$) of$ anhydrous trifluoroacetic acid and the tubes gently flushed with nitrogen. The glass-stoppered tubes were placed at $40^{\circ}$ for $15 \mathrm{~min}$. for the cyclization and cleavage mechanism to be completed. The resulting thiazolinones were extracted with 2-4 ml. of ethylene chloride, the extractions being performed twice on each sample. The ethylene chloride was evaporated in a stream of nitrogen and the thiazolinones were converted into the corresponding phenylthiohydantoins according to the method of Ilse \& Edman (1963). The phenylthiohydantoins were dissolved in ethylene chloride, samples were removed and diluted with ethanol, and spectra were recorded on a Beckman DK-2a ratio recording spectrophotometer. Yields were calculated on the basis of the proper extinction coefficient for the amino acid sub- 
sequently identified (Sjöquist, 1957). Appropriate amounts of the PTH-amino acids* were run in the D, E, F solvent system of Edman \& Sjöquist (1956). Valine was distinguished from phenylalanine in solvent $I$ of the system of Sjöquist (1960). Chromatograms were examined for ultraviolet-absorbing spots and were then sprayed with the iodine-azide reagent (Sjöquist, 1953). Degradative steps on a given peptide were accomplished at the rate of one per day. The peptide chains were stored in a desiccator at $4^{\circ}$ at all times except when being treated, washed or degraded. Certain glutamic acid residues were verified by alkaline hydrolysis of the PTH-amino acid to the free amino acid with $0.2 \mathrm{M}-\mathrm{Ba}(\mathrm{OH})_{2}$ at $120^{\circ}$ in sealed tubes for $20 \mathrm{hr}$. Identification was made by paper electrophoresis. Glutamine and asparagine residues were verified by removing samples of the PTH-amino acids and subjecting them to mild hydrolysis ( $1 \mathrm{~N}-\mathrm{HCl}$ at $100^{\circ}$ for $1 \mathrm{hr}$.). The sample was then rechromatographed and the phenylthiohydantoin of either glutamic acid or aspartic acid identified, as the case may have been. In all cases the reagents were washed or redistilled or both, as specified (Edman \& Sjöquist, 1956).

Miscellaneous methods. The Sakaguchi reagent was prepared and administered as directed by Acher \& Crocker (1952). Ninhydrin-negative material was detected by the chlorine gas method (Rydon \& Smith, 1952). An aniline phthalate spray was used to examine peptides for carbohydrate (Partridge, 1949), and an Ehrlich's test for indoles was conducted with $p$-dimethylaminobenzaldehyde (Reddi \& Kodicek, 1953). The iodine-azide reagent was used as a test for thiol compounds (Chargaff, Levine \& Green, 1948).

\section{RESULTS}

\section{Fibrinopeptide $B$}

Purification. The isolation of lamprey fibrinopeptide B was unknowingly facilitated by clotting lamprey fibrinogen with bovine thrombin. In the best preparations of fibrinogen (from batch I plasma; Doolittle, 1965), the freeze-dried clot liquors needed only to be passed over Sephadex G-25 to be pure enough for direct sequence studies. The concentrated material gave only one band on electrophoresis at $\mathrm{pH} 4 \cdot 1$, and no other components were revealed when the paper strip was stitched tc chromatography paper and subjected to ascending chromatography. The band was ninhydrin-positive and Sakaguchi-positive, and gave a strong reaction with the chlorine gas method of detection. The material was negative to aniline phthalate as a test for carbohydrate, gave a negative Erlich's test and was negative for thiol compounds as determined by spraying with the iodine-azide reagent. The peptide had an $R_{F}$ less than 0.02 in butan-1-ol-acetic acid-water $(4: 1: 5$, by vol.).

Preparations of fibrinopeptide B were also obtained by direct elution from paper strips after electrophoresis of freeze-dried clot liquors. Larger quantities were prepared by adsorption from the

* Abbreviation: PTH-amino acids, phenylthiohydantoin derivatives of amino acids.

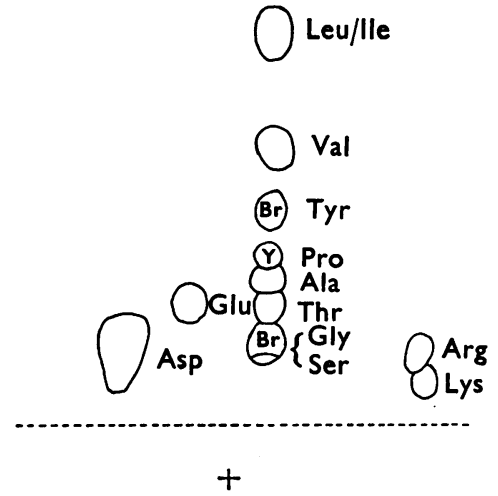

Fig. 1. Tracing of amino acids found on combination paper electrophoresis-paper chromatography after total acid hydrolysis of lamprey fibrinopeptide B. Material was applied at the spot marked by a cross $(+)$ and subjected to electrophoresis at $\mathrm{pH} \mathrm{4 \cdot 1}$. The paper strips were dried and then stitched to chromatography paper for ascending chromatography in butan-1-ol-acetic acid-water $(4: 1: 5$, by vol.) for $17 \mathrm{hr}$. After being thoroughly dried, papers were stained with differential-colour ninhydrin reagent: $Y$, yellow; $\mathrm{Br}$, brown; all other spots various shades of blue. Full details are given in the text.

concentrated clot liquors on to Dowex 1 (X2) columns $(0.9 \mathrm{~cm} . \times 70 \mathrm{~cm}$.) at $\mathrm{pH} 4.5$ and elution at $\mathrm{pH} 2 \cdot 5$. Fibrinopeptide $\mathrm{B}$ could not be adsorbed on Dowex 50 (X2) as can many mammalian fibrinopeptides (cf: Blombäck \& Vestermark, 1958), presumably because of its unusually large size and very high electronegativity.

Amino acid composition. The qualitative amino acid composition of lamprey fibrinopeptide $\mathrm{B}$, as well as its electrophoretic mobility on paper strips, was consistent with that reported for the lamprey 'major' fibrinopeptide by Doolittle, Oncley \& Surgenor (1962), except that at least two additional amino acids (tyrosine and lysine) were detected after acid hydrolysis (Fig. 1). Quantitative amino acid analysis on the micro-chromatographic system indicated that the peptide contained about $\mathbf{4 0}$ amino acid residues (Table 1), the previously undetected amino acids occurring only once each. The peptide contains no phenylalanine, histidine, cysteine, tryptophan or methionine. One residue of isoleucine was identified in the peptide from one batch of lamprey plasma (batch I), but not in another from a different source (batch II). Measurements of amide nitrogen were not made, but the ammonia peak on chromatographic analysis suggested that some of the aspartic acid and glutamic acid residues existed as asparagine and glutamine respectively.

Alkaline hydrolysis revealed that the unusual 


\section{Table 1. Amino acid composition of lamprey fibrinopeptide $B$}

Amino acids are listed in the order in which they emerge from column. Molar ratios were computed by taking the value for aspartic acid to be 13.00. Threonine and serine were corrected for losses during acid hydrolysis (5 and $10 \%$ respectively). Preparation II (from batch I plasma) was purified on Dowex 1 (X2). Preparation IV (from batch II plasma) was purified by elution from paper-electrophoresis strips. In preparation IV, the lysine peak was occluded by the ammonia peak, but the presence of lysine in the peptide was confirmed by paper electrophoresis-paper chromatography. The analyses of preparations II and IV differed significantly with regard to the number of alanine, valine and isoleucine residues.

\begin{tabular}{|c|c|c|c|c|}
\hline & \multicolumn{2}{|c|}{ Preparation II } & \multicolumn{2}{|c|}{ Preparation IV } \\
\hline & $\begin{array}{l}\text { Molar } \\
\text { ratio }\end{array}$ & $\begin{array}{c}\text { Whole } \\
\text { numbers }\end{array}$ & $\begin{array}{l}\text { Molar } \\
\text { ratio }\end{array}$ & $\begin{array}{l}\text { Whole } \\
\text { numbers }\end{array}$ \\
\hline Aspartic acid & $13 \cdot 00$ & 13 & $13 \cdot 00$ & 13 \\
\hline Threonine & $2 \cdot 90$ & $\mathbf{3}$ & $2 \cdot 87$ & 3 \\
\hline Serine & $2 \cdot 51$ & $2-3$ & $1 \cdot 76$ & 2 \\
\hline Glutamic acid & $2 \cdot 79$ & 3 & 2.92 & 3 \\
\hline Proline & $2 \cdot 15$ & 2 & $1 \cdot 61$ & 2 \\
\hline Glycine & $2 \cdot 04$ & 2 & $2 \cdot 10$ & 2 \\
\hline Alanine & $4 \cdot 05$ & 4 & $6 \cdot 38$ & 6 \\
\hline Valine & $2 \cdot 98$ & $\mathbf{3}$ & 1.92 & 2 \\
\hline Isoleucine & $1 \cdot 13$ & 1 & 0 & 0 \\
\hline Leucine & $3 \cdot 64$ & $3-4$ & $3 \cdot 54$ & $3-4$ \\
\hline Tyrosine & 0.93 & 1 & 0.90 & 1 \\
\hline Lysine & 0.64 & 1 & - & (1) \\
\hline Arginine & 0.87 & 1 & 0.79 & 1 \\
\hline Total residue & & $39-41$ & & $39-40$ \\
\hline
\end{tabular}

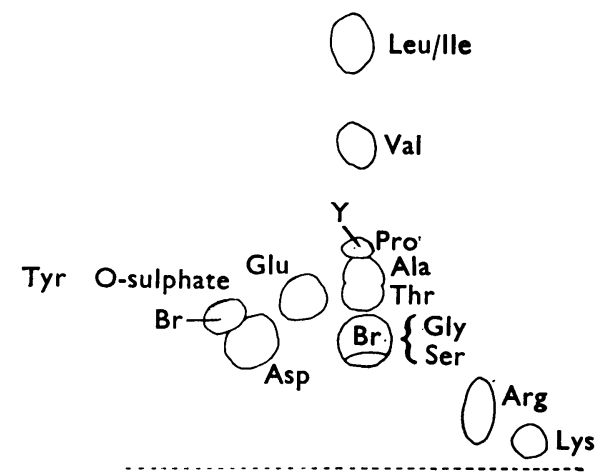

$+$

Fig. 2. Tracing of amino acids found after alkaline hydrolysis of lamprey fibrinopeptide B. The hydrolysate was applied directly to a paper strip, and combination paper electrophoresis-chromatography was conducted as indicated in Fig. 1 except that the $\mathrm{pH}$ was adjusted to 3.9 to improve the separation of tyrosine $O$-sulphate. Free tyrosine was absent. A reference preparation of tyrosine $O$-sulphate was run simultaneously on a companion paper.

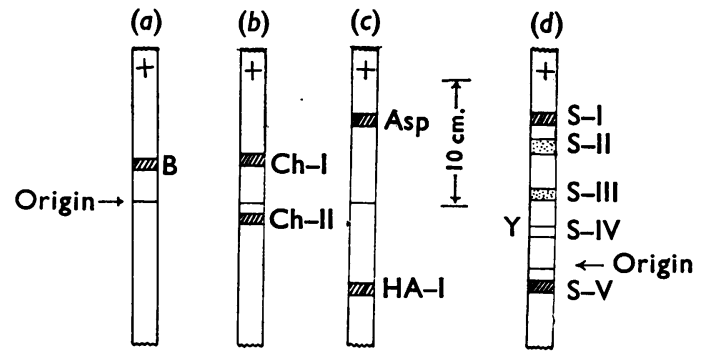

Fig. 3. Paper-electrophoresis strips of various lamprey fibrinopeptide $B$ digestions. (a) Undigested fibrinopeptide B; (b) after digestion with chymotrypsin (Ch); (c) splitting of $\mathrm{Ch}-\mathrm{II}$ with $1 \%$ acetic acid (HA); (d) subtilisin (S) digestion of $\mathrm{Ch}-\mathrm{I}$. Cross-hatched areas, strong blue colour with ninhydrin reagent; stippled area, weak blue colour; $\mathrm{Y}$, yellow. Electrophoresis was carried out at $\mathrm{pH} 4 \cdot 1$ for $(a)-(c)$, and at $\mathrm{pH} 5 \cdot 6$ for $(d)$.

derivative tyrosine $O$-sulphate is present in fibrinopeptide $B$ (Fig. 2). When the peptide is hydrolysed in this way, no free tyrosine is found. The unhydrolysed peptide does not exhibit an absorption peak in the ultraviolet region 270-300 $\mathrm{m} \mu$. Except for the shift of the tyrosine spot to the position of tyrosine $O$-sulphate, paper chromatograms of alkaline hydrolysates were qualitatively the same as those of acid hydrolysates.

Enzymic digestion. Lamprey fibrinopeptide B was not split by trypsin under the conditions described, in spite of the fact that the molecule appears to contain one lysine residue that is neither $N$-nor $C$-terminal. Only one electrophoretic band, identical with that of undigested material, was found after incubation with the enzyme. Descending chromatography also exhibited only the undigested peptide. Under the same conditions, chymotrypsin split fibrinopeptide $B$ into two fragments (Fig. 3). One of these, a small peptide containing arginine, valine and aspartic acid, was isolated both from electrophoretic strips and from paper chromatograms. The other piece after the degradation tended to move with a mobility only slightly greater than that of the undigested peptide. Its $R_{F}$ on paper chromatography was also similar to that of the undigested material. The two chymotryptic fragments are referred to below as Ch-I (the large piece, deduced to be $N$-terminal) and Ch-II (the small piece, deduced to be $C$-terminal). Qualitative analysis of $\mathrm{Ch}-\mathrm{I}$ indicated that arginine was no longer present. Other than that, it was qualitatively similar to the whole fibrinopeptide $B$ in its amino acid composition.

Intact fibrinopeptide $B$ was resistant to the action of carboxypeptidase A. The major fragment after chymotryptic digestion, however, yielded two 
amino acids, (leucine and alanine) after $60 \mathrm{~min}$. digestion with carboxypeptidase $\mathbf{A}$. The leucine residue is thought to be the $C$-terminal residue of the fragment on the basis of the preferential specificity of chymotryptic splitting. Degradation of whole fibrinopeptide $B$ with carboxypeptidase B resulted in the appearance of arginine, valine, leucine and alanine, but not aspartic acid. It was assumed that the carboxypeptidase B preparation contained chymotryptic activity as well as carboxypeptidase A. Arginine was deduced to be the $C$-terminal amino acid of fibrinopeptide $B$, however, since carboxypeptidase $A$ alone did not degrade the peptide.

The $N$-terminal piece derived from chymotryptic studies (Ch-I) was subjected to degradation by subtilisin. At least five major ninhydrin-positive bands were distinguished after paper electrophoresis (Fig. 3). This chymotryptic fragment (Ch-I) was also partially hydrolysed with $1 \%$ acetic acid. Free tyrosine and alanine were detected in the hydrolysate, suggesting that these amino acids had aspartic acid neighbours on both sides. Large quantities of free aspartic acid were also detected. A positively charged peptide was also detected in the mixture after this treatment, as well as an electronegative fragment with a very high $R_{\boldsymbol{F}}$ in butan-1-ol-acetic acid-water (Fig. 4).

The $C$-terminal piece resulting from chymotryptic digestion (Ch-II) was also studied by acetic acid digestion. After the splitting, the peptide gave only one positively charged fragment and free aspartic acid. The positively charged fragment contained only valine and arginine. Since the whole fibrinopeptide contains only one arginine residue, the deduced $C$-terminal dipeptidyl sequence is Val-Arg.

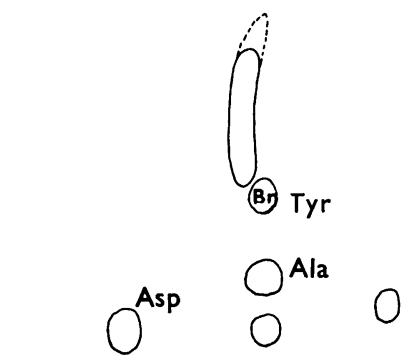

$+$

Fig. 4. Tracing of combination paper electrophoresispaper chromatography of $1 \%$ acetic acid digest of lamprey fibrinopeptide $\mathrm{B}$ chymotryptic fragment $\mathrm{Ch}-\mathrm{I}$. The conditions were as given in Fig. 1.
Edman degradation. Direct sequence studies with the Edman phenyl isothiocyanate method on whole fibrinopeptide $B$ were performed on three separate preparations, all from batch I plasma. A preliminary run (preparation I) indicated that the $N$-terminal tripeptide was Glu-Asp-Ile. The degradation was then carried out on two other preparations, one of which had been purified by stepwise elution from a Dowex 1 (X2) column (preparation II) and the other only by passing the concentrated clot liquor over Sephadex G-25 (preparation III). Preparation III came from a clot liquor that had no detectable extinction at $280 \mathrm{~m} \mu$ after clotting. The sequences of the first seven residues split off by stepwise treatment were identical in both preparations and confirmed the terminal tripeptide found with preparation $I$. Since preparations II and III appeared to have identical sequences, and since only one amino acid was detected at each step in both cases, the two preparations were pooled and the degradation continued through a total of 22 cycles. A total of $20 \mathrm{mg}$. of fibrinopeptide $B$ was used in the degradations. On the basis of the amino acid composition the molecular weight of the peptide was taken to be approx. 4500. With allowances for salt and moisture, a total of 3-4 $\mu$ moles was used in these studies. The stepwise results and yields are given in Table 2. Yields are expressed as percentages of the $\mu$ moles found in the preceding step. The average yield, exclusive of the first and last steps, was $88 \%$. Occasionally a yield would be unusually low if, for example, the extracted thiazolinone was stored in the freezer overnight as a convenience, and not converted into the phenylthiohydantoin until the next day. Since this was not at all related to the state of the peptide remaining to be degraded, the yield of the next step would usually be greater than $100 \%$. Since the yields were based on the extinction of the phenylthiohydantoins before chromatography, the possibility existed that nonspecific absorption in the ultraviolet region was contributing to the high yields. For this reason, the absorption spectra of several steps (11, 15 and 19) are represented in Fig. 5 as evidence that these were true phenylthiohydantoins. Spectra were examined for all steps and found to be consistent. The sequence was stopped, not because the yield fell below detectable levels, but because the chains were out of phase enough to preclude positive identification of the 'new' $N$-terminal residue.

The glutamic acid residues at positions 1 and 10 were subjected to alkaline hydrolysis and the free glutamic acid residues demonstrated. After preliminary identification on chromatography, the PTH-glutamine at position 8 and the PTHasparagine at position 11 were both treated with mild acid and converted into PTH-glutamic acid 
Table 2. Yields of phenylthiohydantoin derivatives of amino acids at each step of the sequence in the degradation of lamprey fibrinopeptide

The amounts of PTH-amino acid were calculated on the basis of spectrophotometric measurements on samples of the converted derivatives before chromatography. The yields are expressed as percentages of the material (in $\mu$ moles) found in the preceding step. Full details are given in the text.

\begin{tabular}{|c|c|c|c|c|}
\hline Step & $\begin{array}{c}\text { PTH-amino acid } \\
(\mu \text { moles })\end{array}$ & Yield (\%) & Result & Traces \\
\hline 1 & $1 \cdot 47$ & - & Glu & - \\
\hline 2 & $1 \cdot 10$ & 74 & Asp & - \\
\hline 3 & $1 \cdot 02$ & 93 & Ile & 一 \\
\hline 4 & 0.97 & 95 & Ser & - \\
\hline 5 & $1 \cdot 00$ & 103 & Leu & - \\
\hline 6 & 0.95 & 95 & Val & - \\
\hline 7 & 0.64 & 67 & Gly & - \\
\hline \multicolumn{5}{|c|}{ (Pooled with $0.3 \mu$ mole from another preparation) } \\
\hline 8 & $0 \cdot 90$ & 94 & Glu( $\left.\mathrm{NH}_{2}\right)$ & (Gly, Glu) \\
\hline 9 & 0.56 & 62 & Pro & - \\
\hline 10 & $0 \cdot 66$ & 118 & Glu & - \\
\hline 11 & $0 \cdot 70$ & 106 & $\operatorname{Asp}\left(\mathrm{NH}_{2}\right)$ & (Glu, Asp) \\
\hline 12 & $0 \cdot 47$ & 67 & Asp & {$\left[\mathrm{Asp}\left(\mathrm{NH}_{2}\right)\right]$} \\
\hline 13 & $0 \cdot 43$ & 92 & Tyr & (Asp) \\
\hline 14 & $0 \cdot 46$ & 107 & Asp & (Tyr) \\
\hline 15 & $0 \cdot 34$ & 74 & Thr & (Asp, dehydrothreonine) \\
\hline 16 & 0.29 & 85 & Gly & - \\
\hline 17 & $0 \cdot 29$ & 100 & Asp & (Gly) \\
\hline 18 & $0 \cdot 31$ & 107 & Asp & (Gly) \\
\hline 19 & $0 \cdot 23$ & 74 & Asp, Ala & - \\
\hline 20 & $0 \cdot 19$ & 83 & Ala, Asp & (Thr) \\
\hline 21 & $0 \cdot 19$ & 100 & Asp, Ala, Asp( $\left.\mathrm{NH}_{2}\right)$ & - \\
\hline 22 & $0 \cdot 29$ & 153 & Asp, Ala & - \\
\hline
\end{tabular}

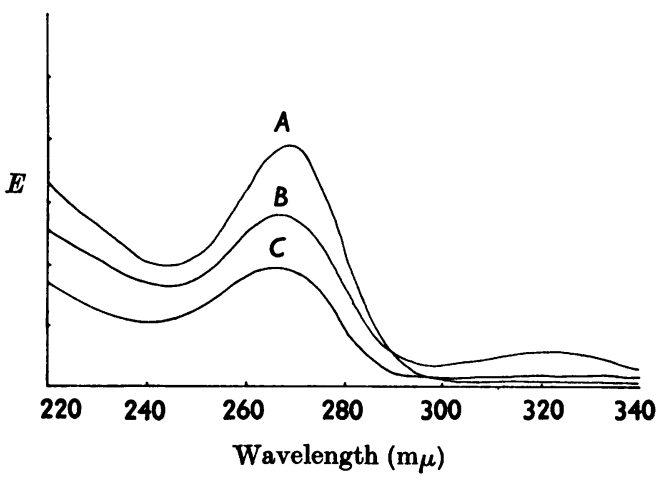

Fig. 5. Absorption spectra of PTH-amino acids derived from lamprey fibrinopeptide $\mathrm{B}: A$, step $11 ; B$, step 15; $C$, step 19. In step 11 , the phenylthiohydantoin was dissolved in $150 \mu \mathrm{l}$. of ethylene chloride. In steps 15 and 19, the preparations were dissolved in $100 \mu \mathrm{l}$. of ethylene chloride. In each case $5 \mu$ l. of the ethylene chloride solution was diluted with $1.0 \mathrm{ml}$. of ethanol for reading on the Beckman DK-2a ratio recording spectrophotometer. Step 11 was found to be asparagine, step 15 threonine and dehydrothreonine, and step 19 a mixture of aspartic acid and alanine (cf. Table 2). and PTH-aspartic acid respectively. The isoleucine at position 3 was identified on the basis of repeated runs in solvent D (Edman \& Sjöquist, 1956). In all cases the sample moved with the isoleucine rather than with the closely related leucine. The valine at position 6 was originally identified in solvent $D$ and was subsequently verified in Sjöquist's (1960) solvent I. Serine was verified in step 4 by the nature of the characteristic spectrum of its derivative before chromatography.

\section{Fibrinopeptide $A$}

Isolation. Lamprey fibrinopeptide A was isolated from the clot liquors of fibrin A preparations as well as from fibrin $B$ treated with lamprey thrombin (Doolittle, 1965). In some cases the peptide was eluted from paper strips after electrophoresis of concentrated clot liquors or filtrates. In others it was separated from the bulk of the fibrinopeptide $B$ or contaminating substances by extraction of the freeze-dried clot liquor with $50 \%$ (v/v) propan-2-ol or $75 \%(v / v)$ acetone. The propan-2-ol or acetone extracts were evaporated to dryness, and the 


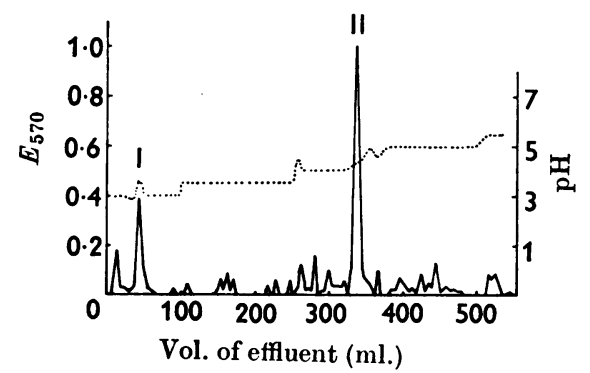

Fig. 6. Column chromatography on a Dowex 50 (X2) column $(0.9 \mathrm{~cm} . \times 60 \mathrm{~cm}$.) of a $50 \%$ propan-2-ol extract of freeze-dried filtrate obtained after treating lamprey fibrin B (obtained with bovine thrombin) with lamprey thrombin. Only free amino acids were found in peak I. Peak II was lamprey fibrinopeptide A. - Ninhydrin colour read at $570 \mathrm{~m} \mu ; \ldots . . ., \mathrm{pH}$.

material was redissolved in water and subjected to chromatography on a Dowex 50 (X2) column $(0.9 \mathrm{~cm} . \times 50 \mathrm{~cm}$. $)$. On stepwise elution, the peptide emerged from the column at $\mathrm{pH} 4.5$ (Fig. 6). Preliminary separation of the peptide from the much larger fibrinopeptide $B$ could also be accomplished on Sephadex G-25, the small fibrinopeptide A being retained to a greater degree by the gel column $(2.5 \mathrm{~cm} . \times 40 \mathrm{~cm}$. $)$.

Amino acid composition. Total acid hydrolysis revealed that the peptide contains only five different amino acids. Its empirical amino acid composition as determined on the micro-chromatographic apparatus is $\mathrm{Asp}_{3}, \mathrm{Ser}_{2}, \mathrm{Ile}_{1}, \mathrm{Leu}_{1}, \mathrm{Arg}_{1}$.

Enzymic digestions. Under the conditions described above, the peptide was resistant to the action of trypsin, chymotrypsin and carboxypeptidase $A$. Degradation with carboxypeptidase $B$ for $30 \mathrm{~min}$. released free arginine and leucine or isoleucine (the two amino acids could not be accurately distinguished by combination paper electrophoresispaper chromatography). The mixture contained only one other ninhydrin-positive substance, an electronegative peptide containing aspartic acid, serine and leucine or isoleucine. The peptide fragment was not Sakaguchi-positive, nor was arginine found after acid hydrolysis.

Partial hydrolysis with acetic acid. Partial hydrolysis with $1 \%$ acetic acid resulted in free aspartic acid, one neutral peptide, and one positively charged peptide ( $\mathrm{pH} 4 \cdot 1$ ). The neutral peptide contained serine and leucine or isoleucine; the positive fragment contained arginine, serine and leucine or isoleucine.

Edman degradation. Stepwise degradation of $1.9 \mathrm{mg}$. of fibrinopeptide $A$ by the Edman phenyl isothiocyanate method yielded a terminal tripeptide sequence of Asp-Asp-Ser. At the end of
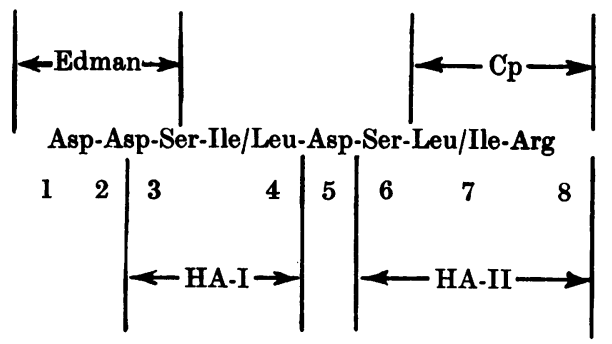

Fig. 7. Summary of sequence information concerned with lamprey fibrinopeptide A. Edman, phenyl isothiocyanate degradation; HA-I and HA-II, fragments obtained with $1 \%$ acetic acid partial hydrolysis; $\mathrm{Cp}$, treatment of fibrinopeptide with carboxypeptidase $B$.

the three cycles, a peptide bearing a slight positive charge at $\mathrm{pH} 4 \cdot 1$ was isolated from the degradation residue. The fragment contained aspartic acid, serine, leucine or isoleucine and arginine. The yield of PTH-aspartic acid released after the first degradation of the fibrinopeptide A was $50 \%$ when calculated on the basis of the molecular weight of the octapeptide indicated by the quantitative amino acid composition. This value, uncorrected for salt and moisture, compared favourably with the first-step yields obtained with ten mammalian fibrinopeptides isolated under similar conditions by Blombäck \& Doolittle (1963).

The deduced amino acid sequence of lamprey fibrinopeptide $A$ is presented in Fig. 7. The relative positioning of the leucine and isoleucine residues is as yet unknown, although the fact that the peptide is resistant to the action of chymotrypsin suggests that the leucine is penultimate to the $C$-terminal end.

\section{DISCUSSION}

The characterization of the two lamprey fibrinopeptides has been handicapped to a degree by the limited amounts of material available for analysis. Since the animals can only be caught during one month of a year during their spawning run, some equivocal judgements have to be made about how to deploy a year's supply of material. In the present report the preliminary characterization is unusual in that considerably more material has been devoted to determining part of the sequence of lamprey fibrinopeptide $\mathbf{B}$ by the direct Edman method than has been allotted for precise quantitative amino acid analysis of the entire molecule. These judgements were made concordant with the facilities available. Thus there is still some doubt about the exact amino acid composition of fibrinopeptide B (Table 1), since in two different analyses three of the 13 amino acids found after 
acid hydrolysis differed significantly on a molarratio basis. It is possible that the two different preparations did differ slightly since they were isolated from two different populations of animals. On the other hand, the differences are not so great that experimental variation in the purification and micro-chromatographic analysis can be ruled out.

On the other hand, the $N$-terminal sequence of fibrinopeptide B as established by the Edman method is clear. The first 18 residues are unambiguous. In the last four degradative cycles, the trailing from preceding steps made the assignment of the new residues unclear. The emphasis on the direct sequence method stemmed partly from interest in the tyrosine $O$-sulphate residue isolated after alkaline hydrolysis. The residue had previously been found in six of seven mammalian fibrinopeptides B (Bettelheim, 1954; Blombäck, Boström \& Vestermark, 1960; Blombäck \& Doolittle, 1963), and there was hope of establishing a definite homologous relationship between the fibrinopeptide $B$ of the primitive fish and those of higher animals. If the sulphated tyrosine occurred near the end of the chain, as it does in the known mammalian fibrinopeptides $B$, then stepwise degradation of the end of the peptide might provide comparative data that would be conceivably more useful than precise amino acid composition determinations. In fact, the single tyrosine residue occurred in the thirteenth position from the $N$-terminal end. It was preceded and followed by aspartic acid residues, just as it is in all six of the mammalian fibrinopeptides $B$ that contain this residue. This finding was consistent with the results of acetic acid splitting, which released free tyrosine. It seems probable that the tyrosine is sulphated after its incorporation into the fibrinogen chain, and that the sulphation, whether spontaneous or enzymic, demands the Asp-Tyr-Asp sequence. This tripeptide sequence was the only one found in the $N$-terminal region of the molecule that bore any resemblance to those of mammalian fibrinopeptides, which are themselves highly variable. It is unlikely that the tyrosine $O$-sulphate plays any role in thrombin attachment, since in the lamprey fibrinopeptide it is considerably more distant (in terms of number of residues) from the vulnerable arginyl-glycine junction than is the case in the mammalian fibrinopeptides. On the other hand, the persistence of the sequence through 400000000 years of evolution suggests some physiological role for the tyrosine $O$-sulphate. It may have a role either in fibrinogen dispersal or in other phases of the haemostatic process after its release from the parent fibrinogen molecule.

The fact that lamprey fibrinopeptide $B$ is resistant to attack by trypsin may hinder the completion of the amino acid sequence determination. Splitting with subtilisin, howevar, seems to offer a promising method of attack.

Whereas lamprey fibrinopeptide $B$ is the largest fibrinopeptide yet discovered, being roughly twice as long as bovine fibrinopeptide B, lamprey fibrinopeptide $A$ is the smallest yet uncovered. With the exception of the $C$-terminal arginine residue, the peptide bears no resemblance to mammalian fibrinopeptides $\mathrm{A}$. The known mammalian fibrinopeptides $A$ do have a great deal of correspondence in parts of their amino acid sequences, and the radical departure of the lamprey fibrinopeptide may account for its not being released by bovine thrombin. The extreme variability of the fibrinopeptides $B$ that are released by bovine thrombin argues against such reasoning, however (cf. Doolittle \& Blombäck, 1964). The most significant difference in sequence apparent from comparisons of the lamprey fibrinopeptides with their proposed mammalian homologues is concerned with the amino acids at the second position from the $C$-terminal end. In the mammalian fibrinopeptides $A$ and $B$, only valine or alanine is found at that position. In the lamprey fibrinopeptide $\mathrm{B}$, that position is occupied by valine, and the fibrinopeptide is released by bovine thrombin. In fibrinopeptide $A$, however, that position is occupied by a leucine or isoleucine residue. Since this position is adjacent to the link that is attacked by thrombin, it is possible that the larger leucine (or isoleucine) residue can block the approach of the bovine thrombin. In terms of the classical 'lock-and-key' hypothesis, it is not difficult to visualize a valine fitting into a leucine 'hole', but the inverse may not be possible.

I express my gratitude to Professor E. Jorpes and Dr B. Blombäck, in whose Laboratories these experiments were conducted. I am especially grateful to my sponsor, Dr B. Blombäck, for his instruction in the use of the Edman method, and to A. Baldesten for conducting the quantitative amino acid analyses. The technical assistance of Mr P. Nilsson and Miss Gunilla Croneborg is gratefully acknow. ledged. This investigation was supported in part by U.S. Public Health Service Fellowship no. HE-14057, and by Grant no. HE 7379-01, U.S. National Institutes of Health, to Dr B. Blombäck.

\section{REFERENCES}

Acher, R. \& Crocker, C. (1952). Biochim. biophys. Acta, 9, 704.

Bettelheim, F. R. (1954). J. Amer. chem. Soc. 76, 2838.

Blackburn, S. \& Lee, G. R. (1954). Biochem. J. 58, 227.

Blombäck, B., Boström, H. \& Vestermark, A. (1960). Biochim. biophys. Acta, 38, 502.

Blombäck, B. \& Doolittle, R. F. (1963). Acta chem. scand. 17, 1819.

Blombäck, B. \& Vestermark, A. (1958). Ark. Kemi,12, 173. Chargaff, E., Levine, C. \& Green, C. (1948). J. biol. Chem. 175, 67. 
Doolittle, R. F. (1965). Biochem. J. 84, 735.

Doolittle, R. F. \& Blombäck, B. (1964). Nature, Lond., 202, 147.

Doolittle, R. F., Oncley, J. L. \& Surgenor, D. M. (1962). J. biol. Chem. 237, 3123.

Edman, P. (1950). Acta chem. scand. 4, 283.

Edman, P. (1960). Ann. N.Y. Acad. Sci. 88, 602.

Edman, P. \& Sjöquist, J. (1956). Acta chem. scand. 10, 1507.

Hamilton, P. B. (1963). Analyt. Chem. 35, 2055.

Hirs, C. H. W., Moore, S. \& Stein, W. H. (1956). J. biol. Chem. 219, 623.

Ilse, D. \& Edman, P. (1963). Aust. J. Chem. 16, 411.
McMenamy, R. H., Lund, C. C. \& Oncley, J. L. (1957). $J$. clin. Invest. 36, 1672.

Moore, S. \& Stein, W. H. (1954a). J. biol. Chem. 211, 893.

Moore, S. \& Stein, W. H. (1954b). J. biol. Chem. 211, 907.

Partridge, S. M. (1949). Nature, Lond., 164, 443.

Reddi, K. K. \& Kodicek, E. (1953). Biochem. J. 53, 286.

Rydon, H. N. \& Smith, P. W. G. (1952). Nature, Lond., 169, 922.

Sjöquist, J. (1953). Acta chem. scand. 7, 447.

Sjöquist, J. (1957). Ark. Kemi, 11, 129.

Sjöquist, J. (1960). Biochim. biophys. Acta, 41, 20.

Spackman, D. H., Stein, W. H. \& Moore, S. (1958). Analyt. Chem. 30, 1190. 